\title{
Potash mining effluents and ion imbalances cause transient osmoregulatory stress, affect gill integrity and elevate chronically plasma sulfate levels in adult common roach, Rutilus rutilus
}

Nora Baberschke, Katja Irob, Torsten Preuer, Thomas Meinelt, Werner Kloas [ (ㄴ) https://orcid.org/0000-0001-8905$\underline{183 X}$

DOI

10.1016/i.envpol.2019.03.004

Original publication date

12 March 2019 (Available online)

\section{Document version}

Accepted manuscript

Published in

Environmental Pollution

Citation

Baberschke N, Irob K, Preuer T, Meinelt T, Kloas W. Potash mining effluents and ion imbalances cause transient osmoregulatory stress, affect gill integrity and elevate chronically plasma sulfate levels in adult common roach, Rutilus rutilus. Environmental Pollution. 2019;249:181-90. 


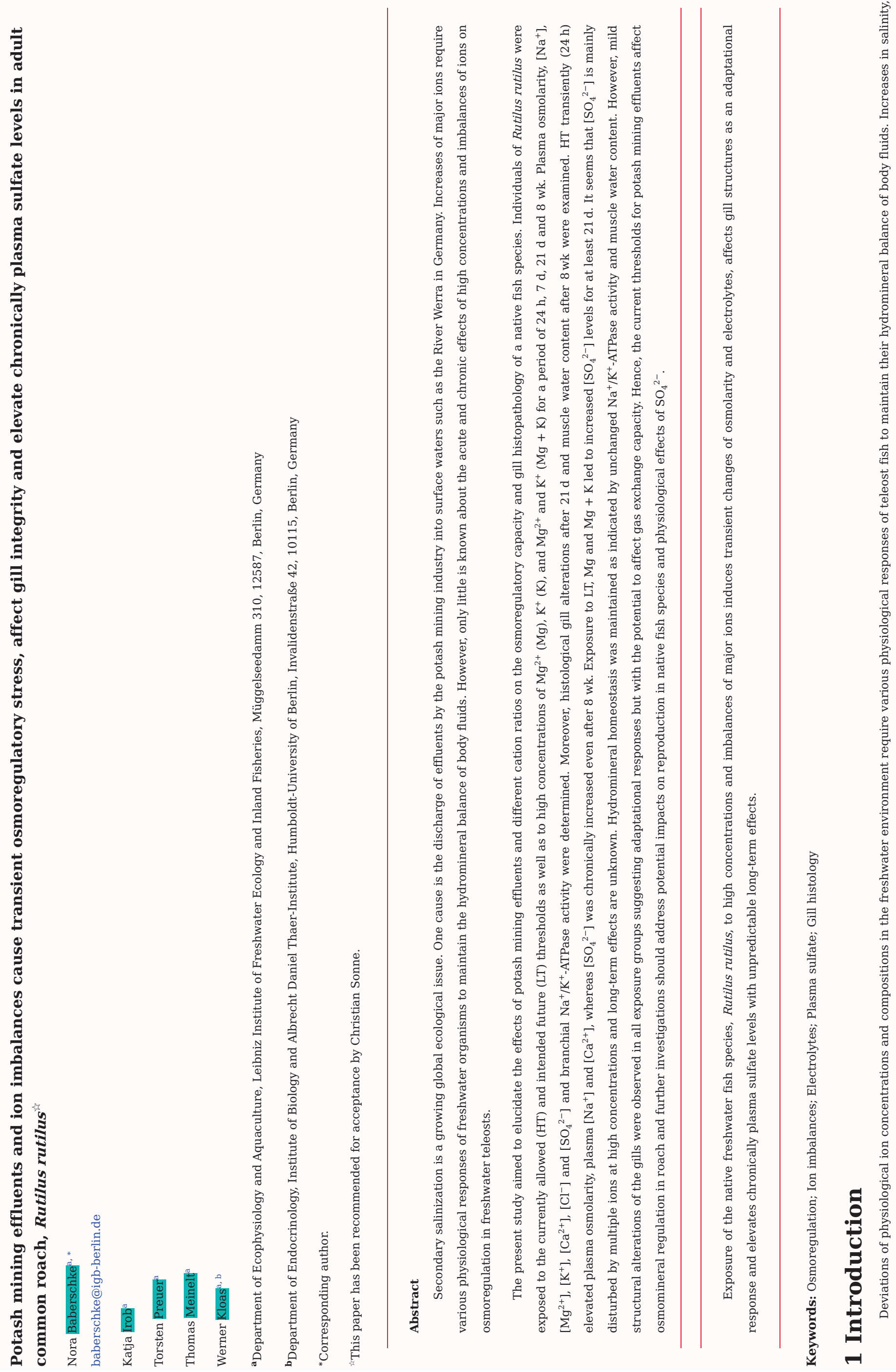


HI

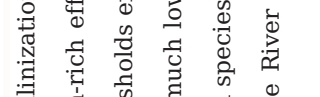

MIII

IIIIII

m

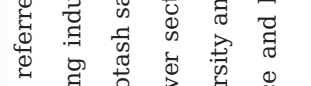

In

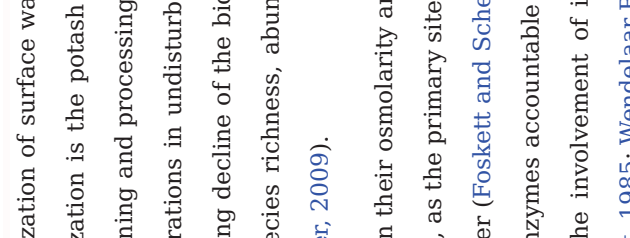

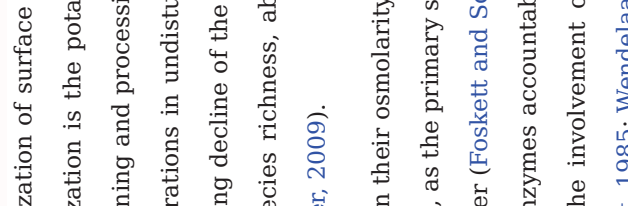

IIIIIIII

I H

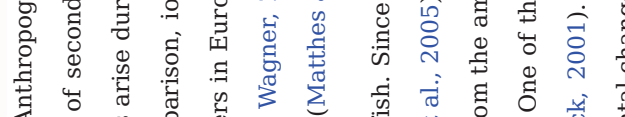

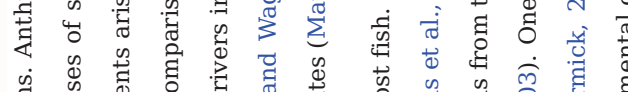

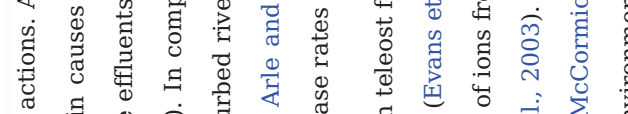

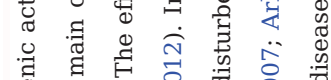

1

IIIIIII

列

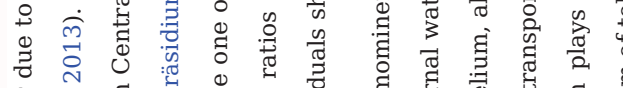

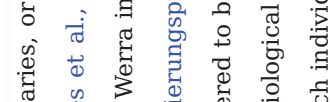

III

In

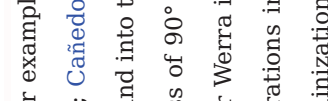

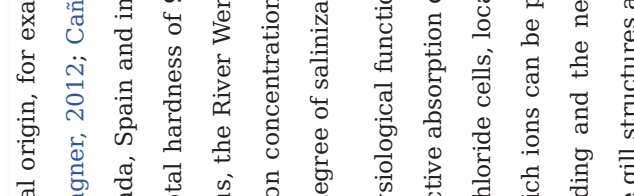

IIIIIIIIIIIIIIIIIIII

II

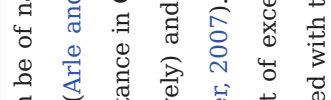

告高竞

1

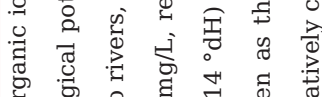

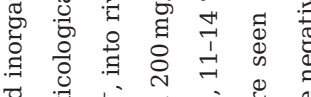

I

HIIIIIIIII

H

In

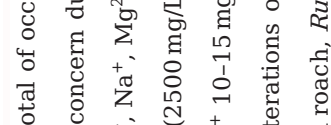

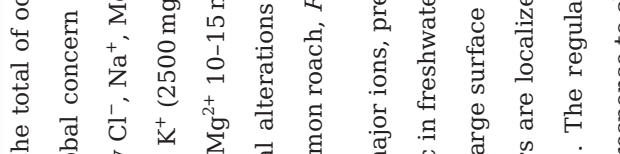

新着率 


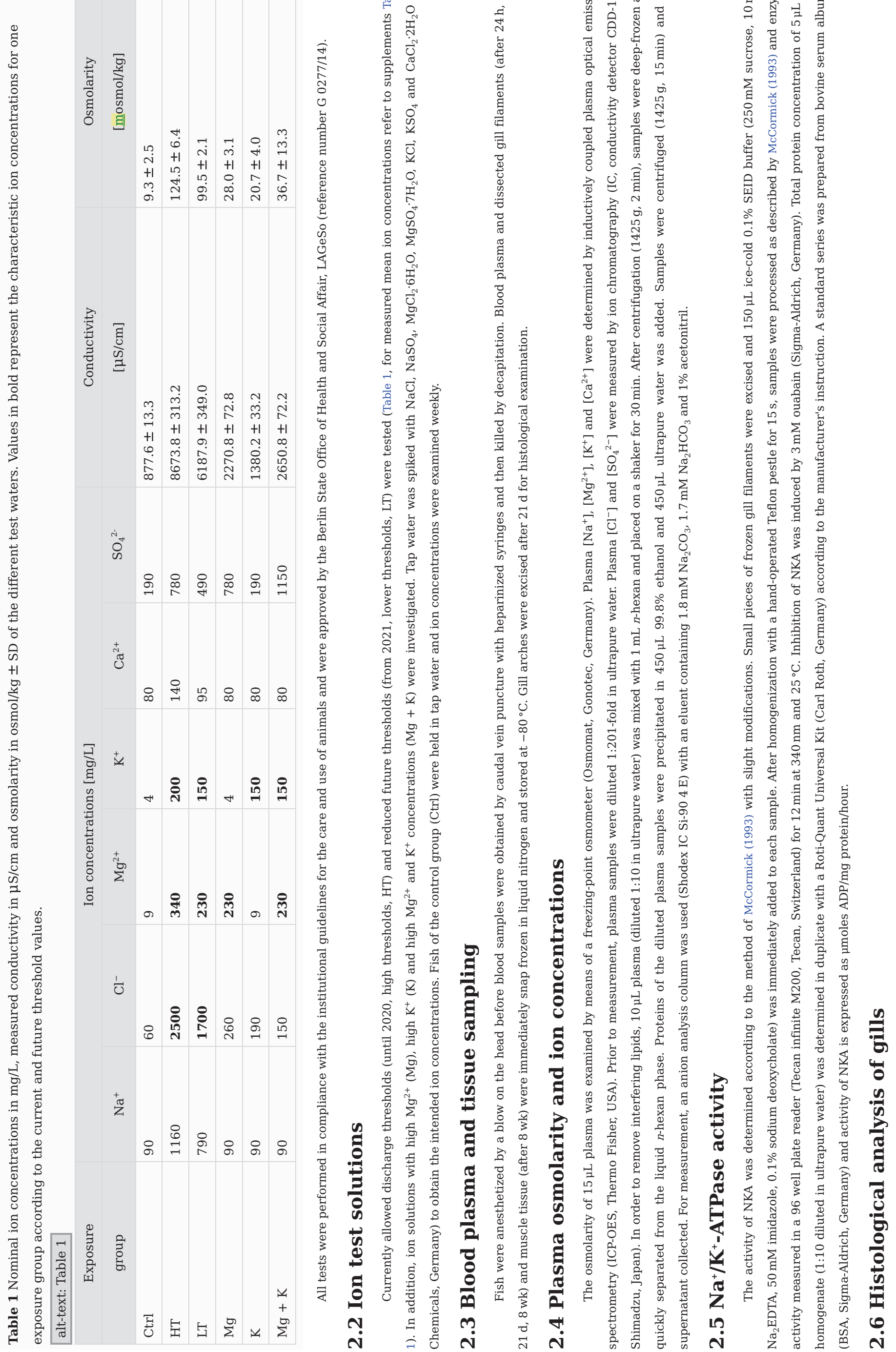









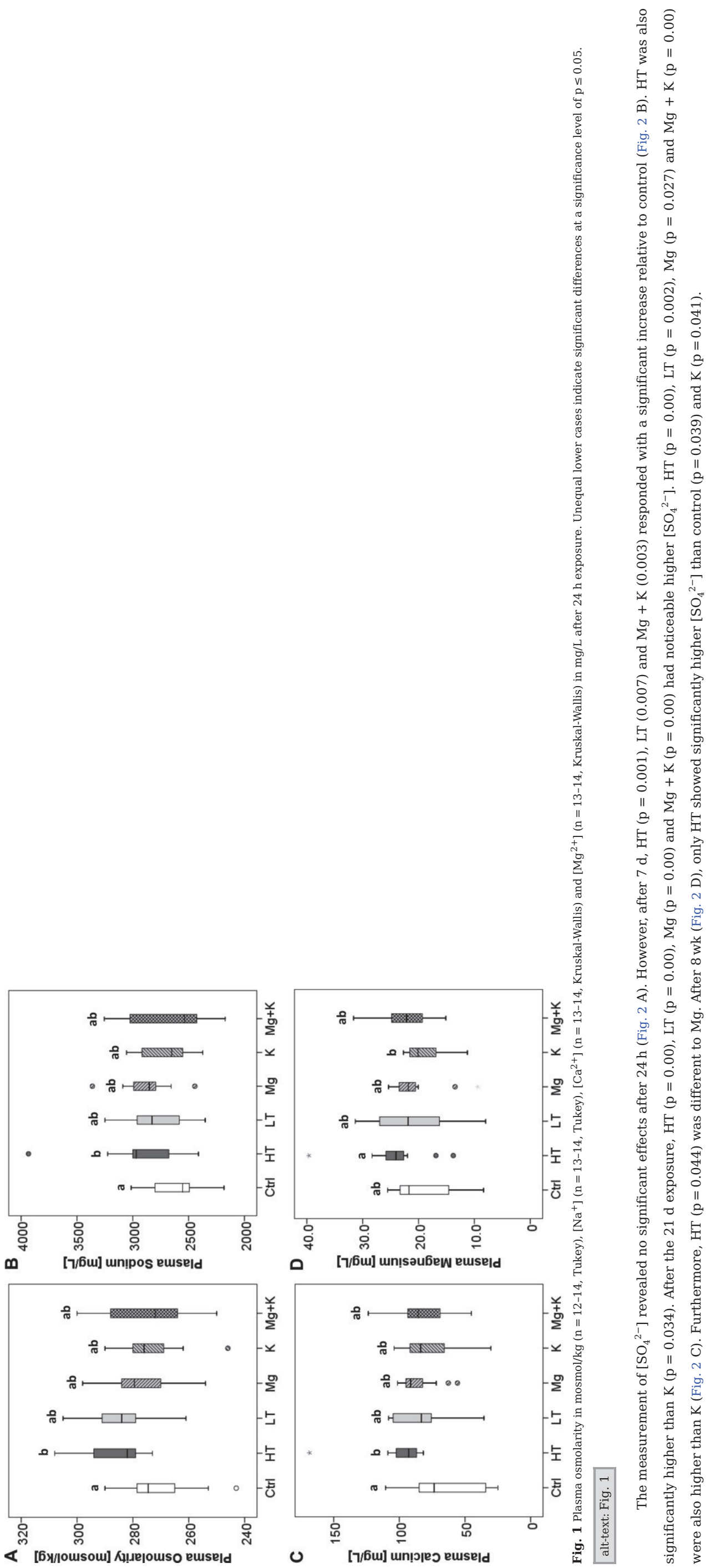




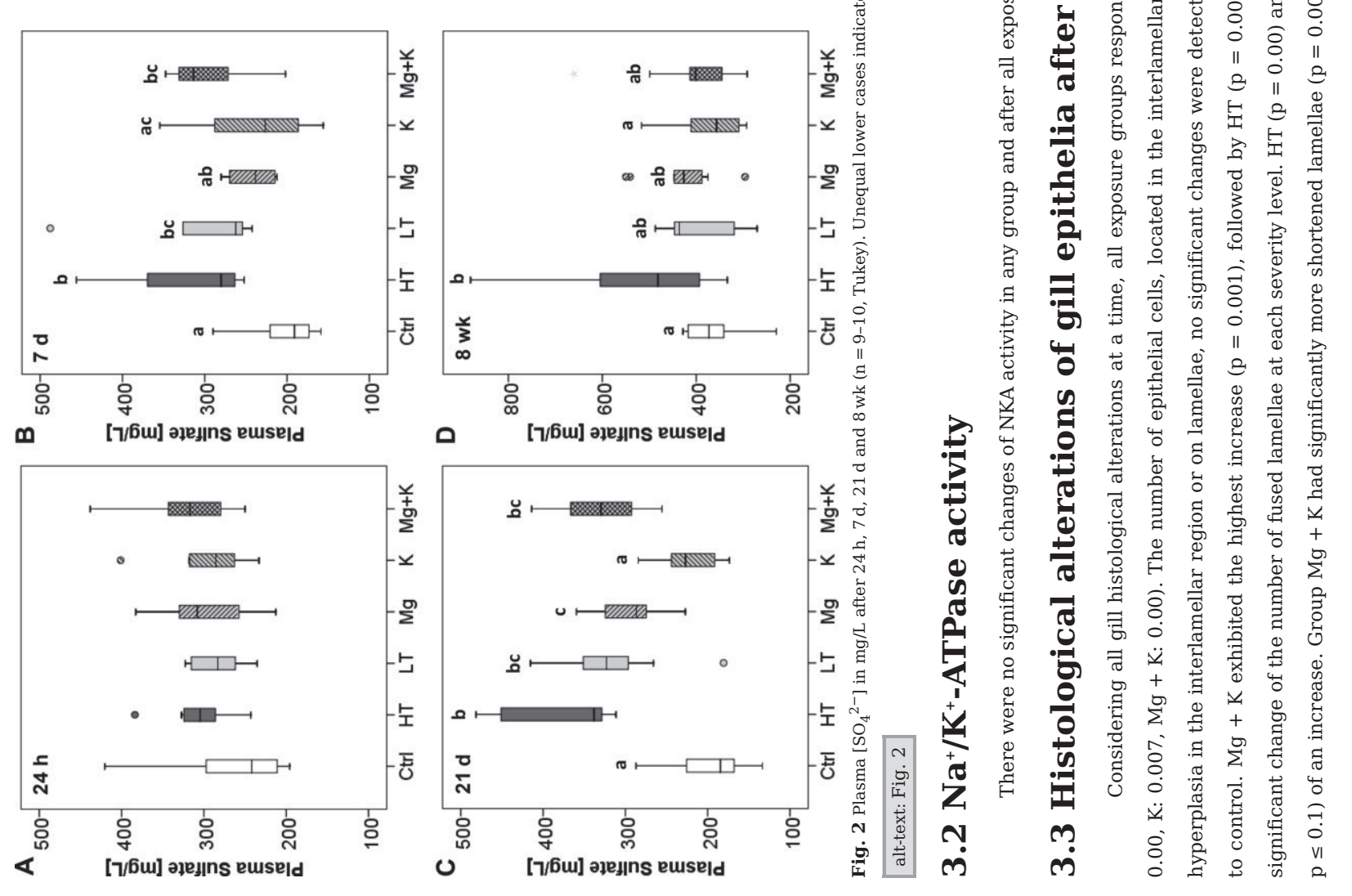




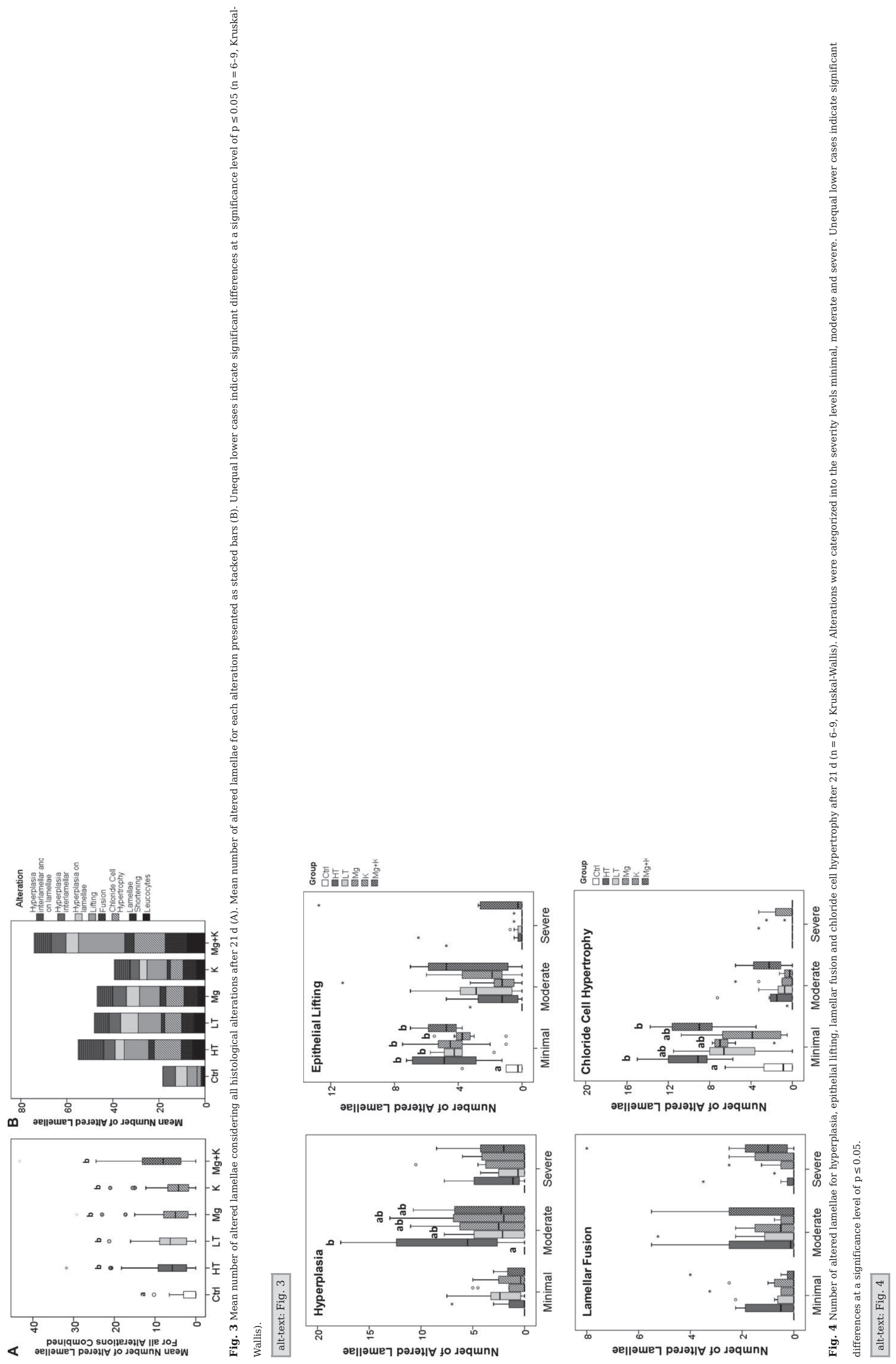




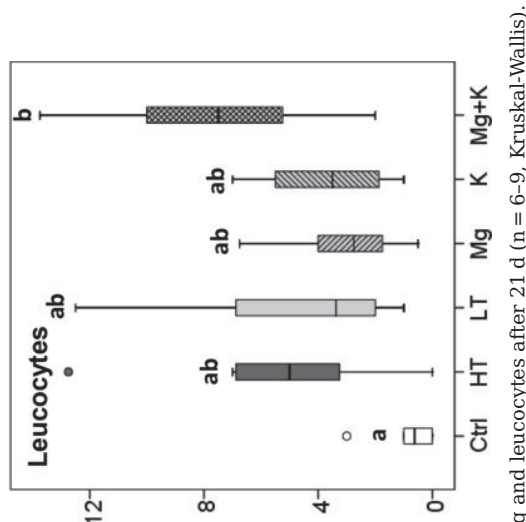

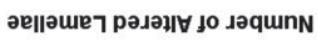

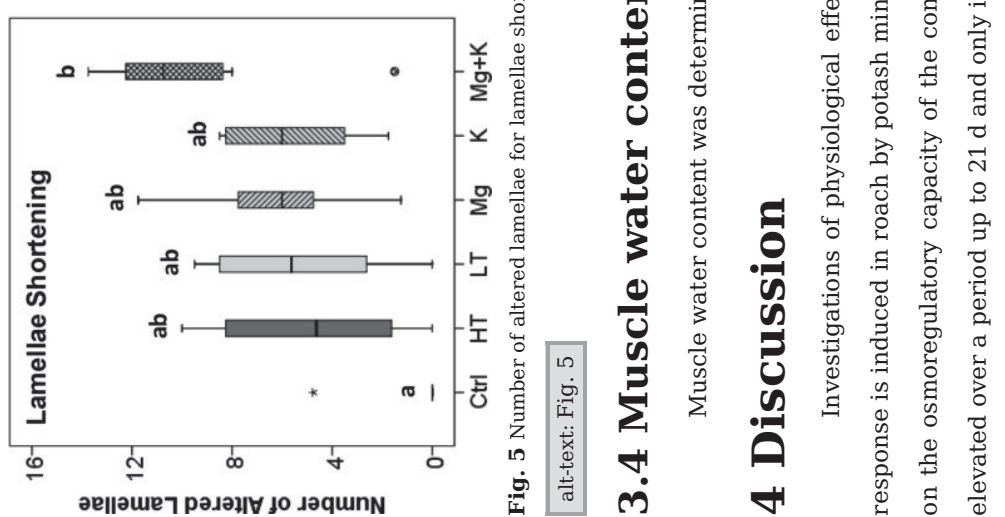




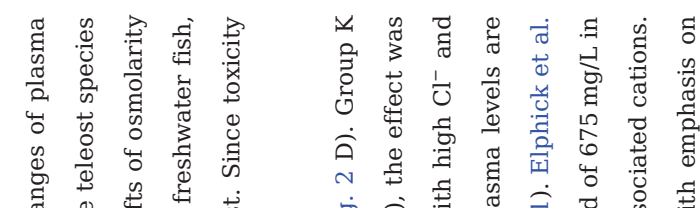

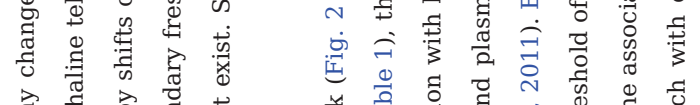

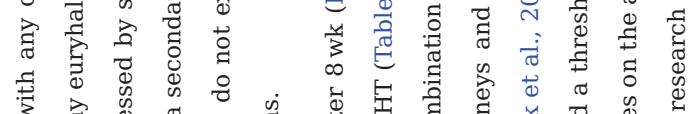

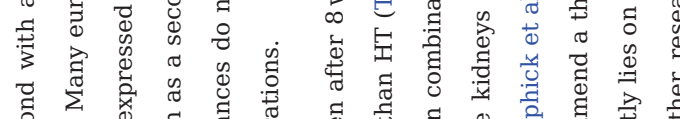

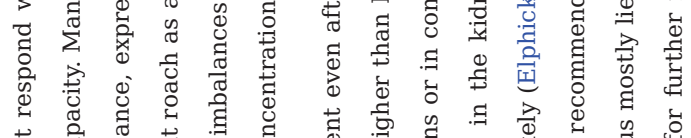

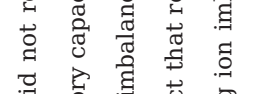

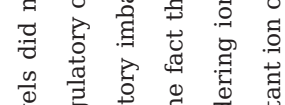

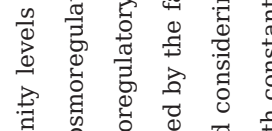

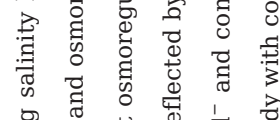

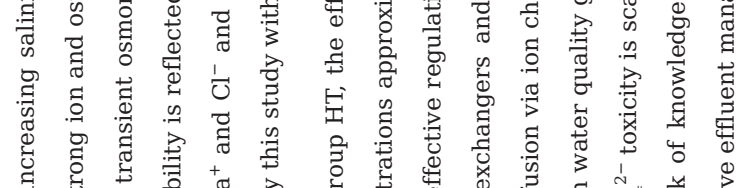

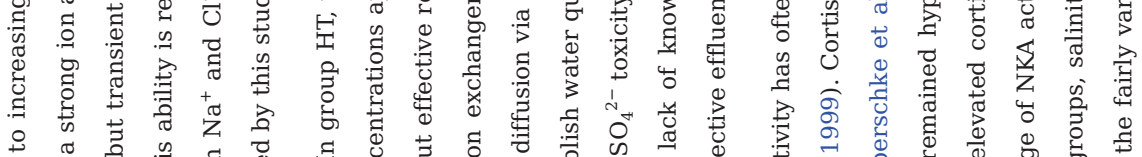

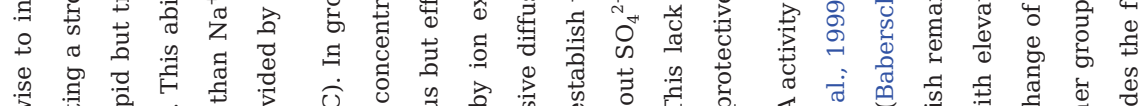

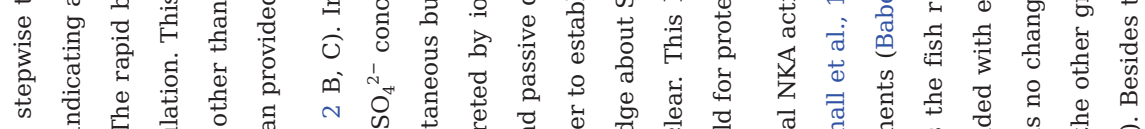

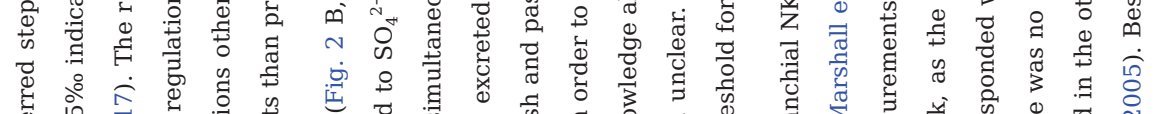

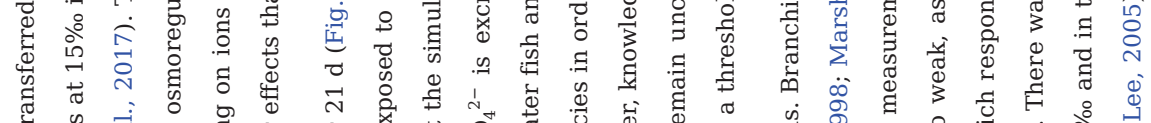

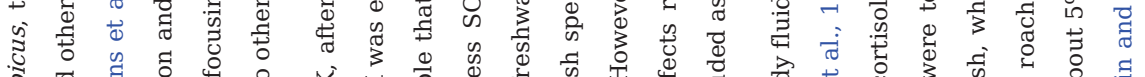

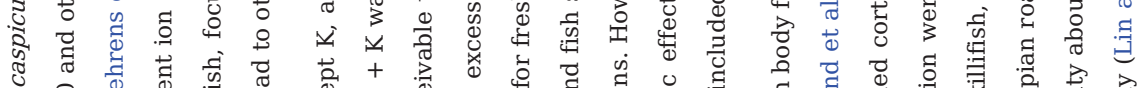

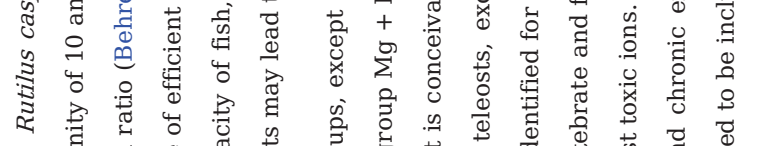

穿节

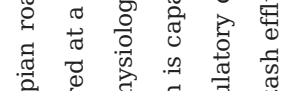

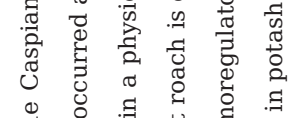

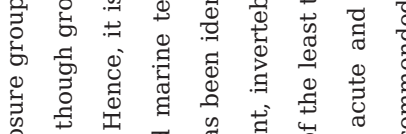

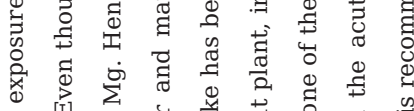

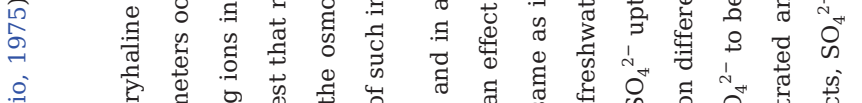

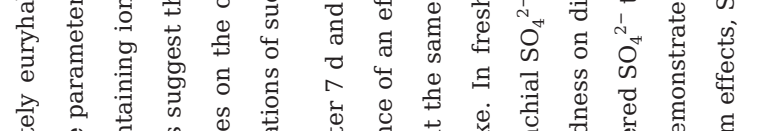

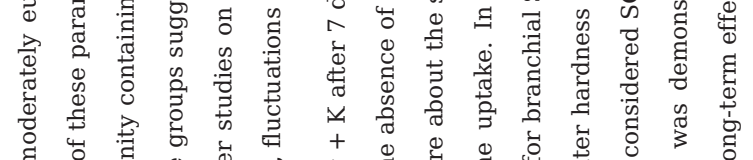

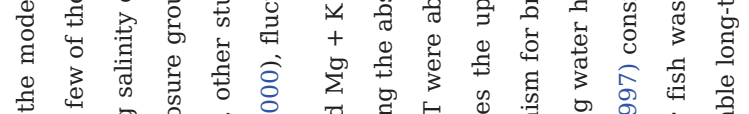

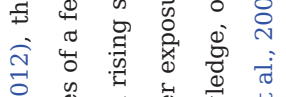

范

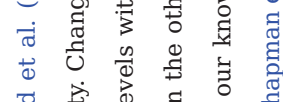

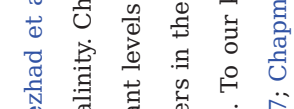

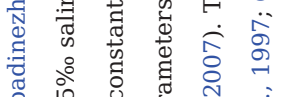

藏

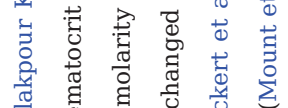

零

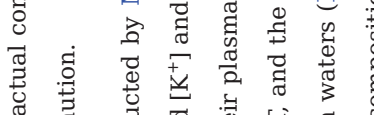

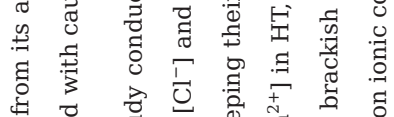

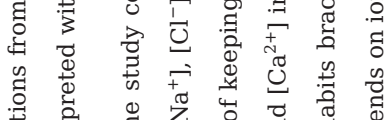

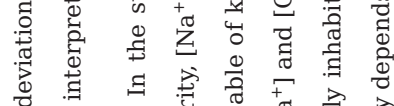

ठ

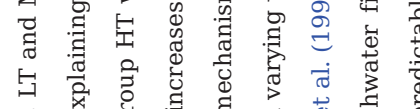

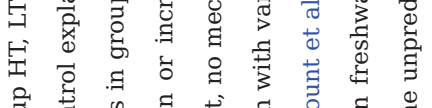

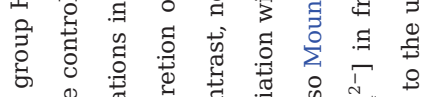

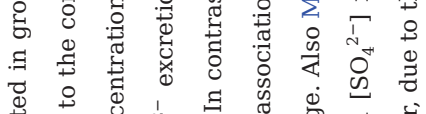

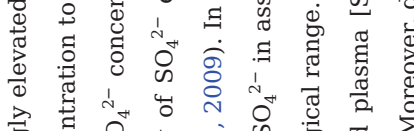

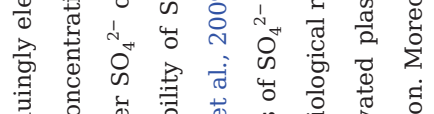

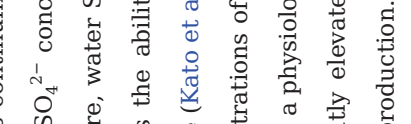

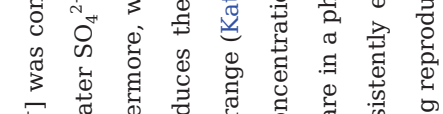

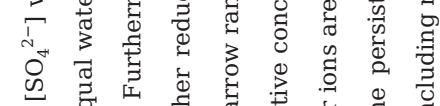

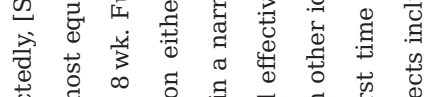
总焉

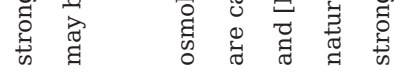

\section{(1)}

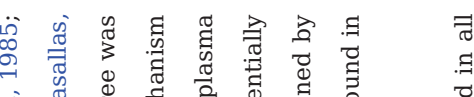

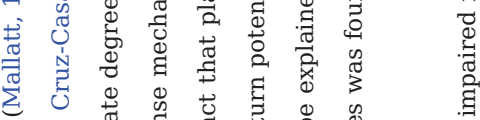

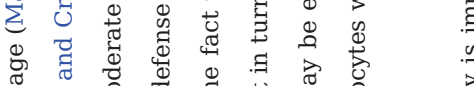

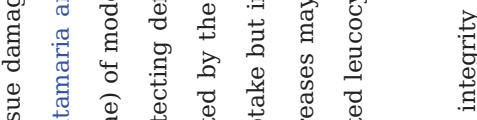

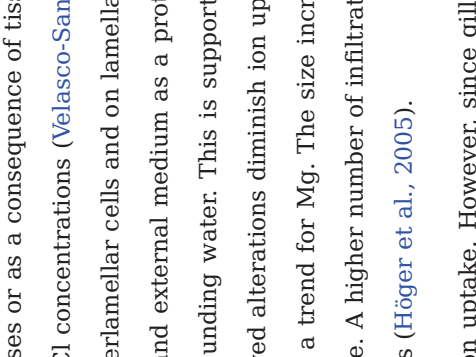

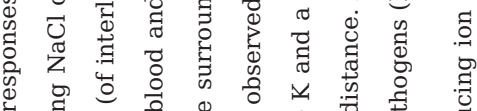

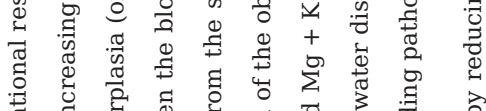

䒕寻芯

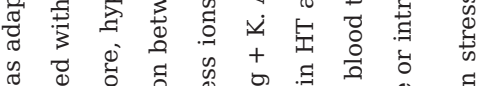

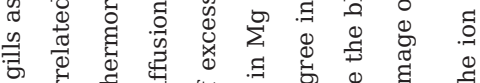

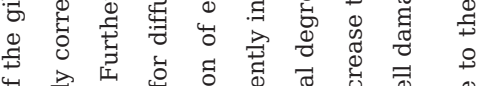

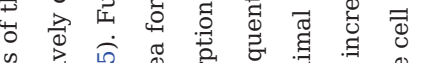

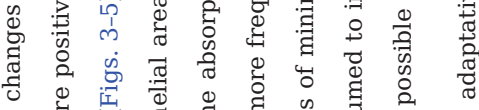

苋

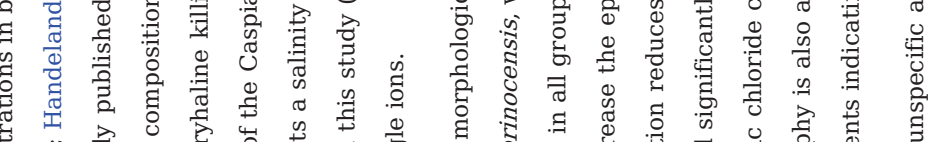

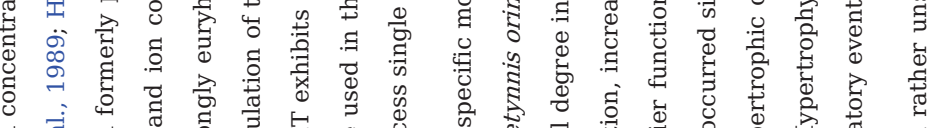

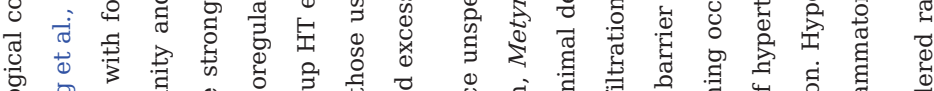

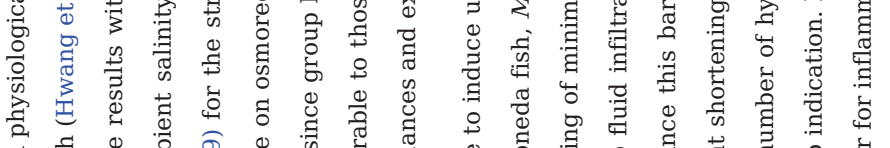

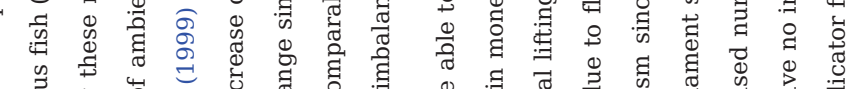

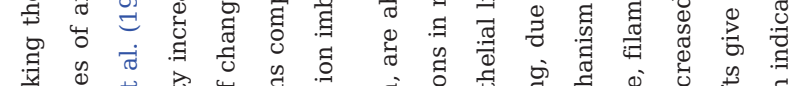

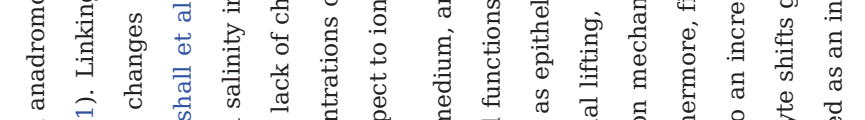

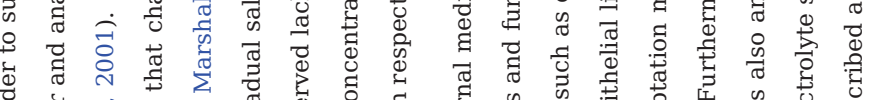
焉 氶

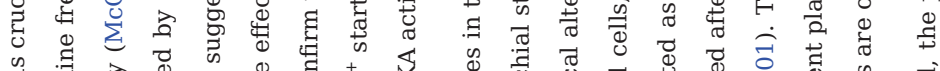

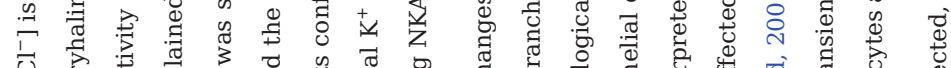

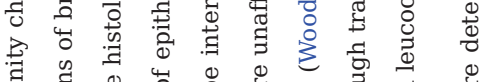

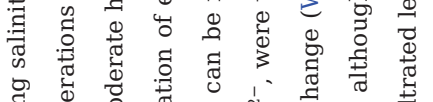

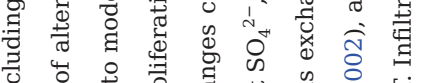

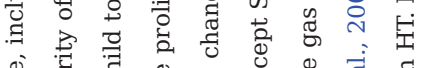

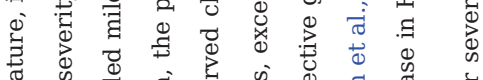

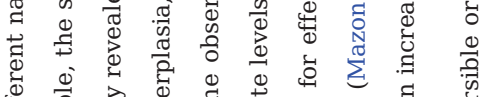

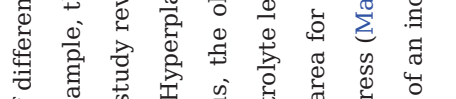

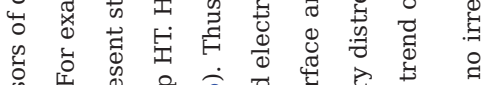

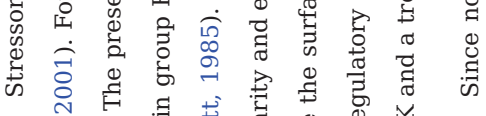

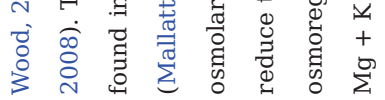




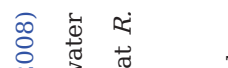

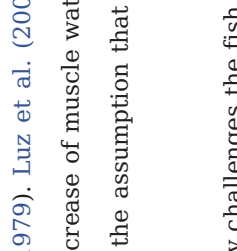

จ वี

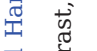

घี

这.

量

苟

త్తి

त्र

范

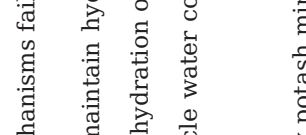

घ

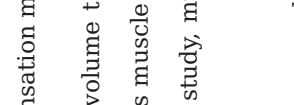

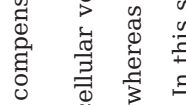

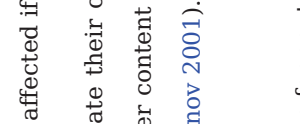

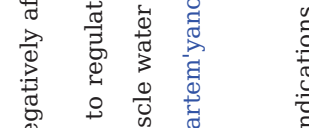

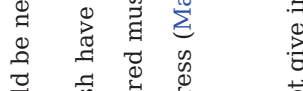

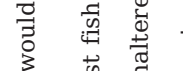

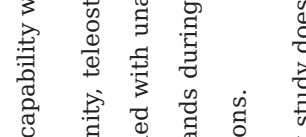

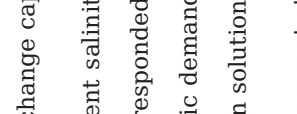

है

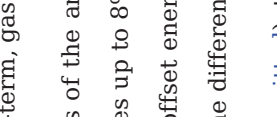

苟

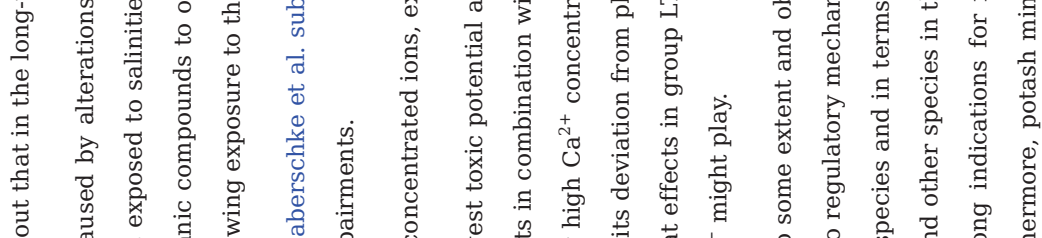

ฮ

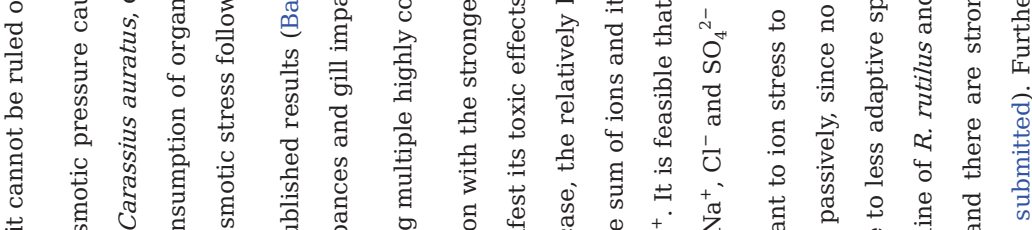

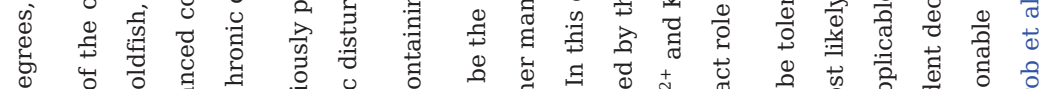

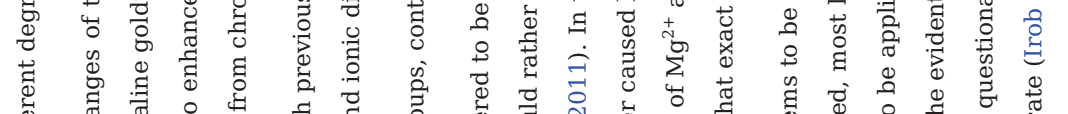

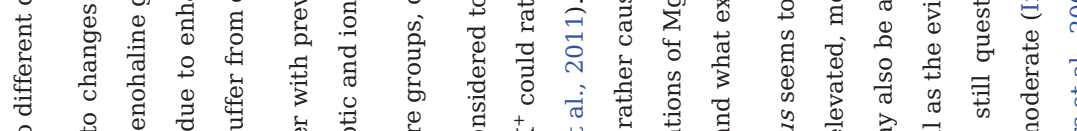

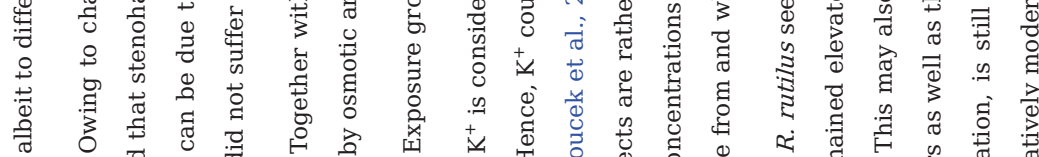

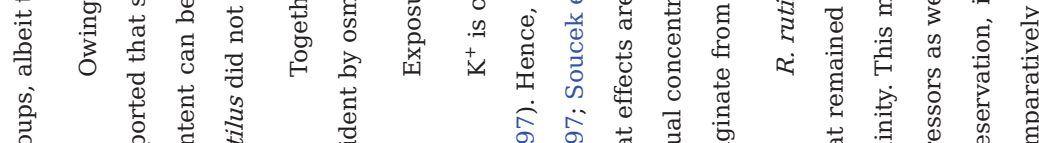

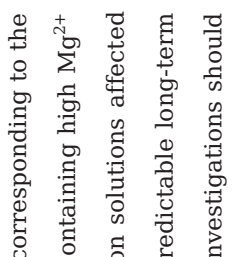

萡

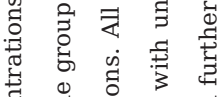

茙

ठี

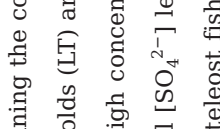

䓠

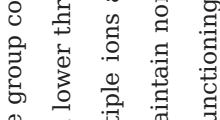

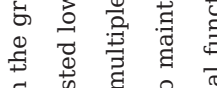

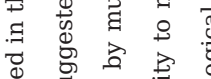

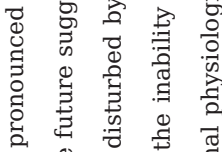

落

苟

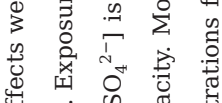

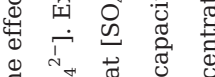

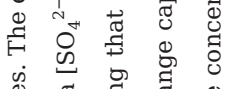

它

ब

节荡

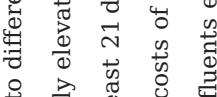

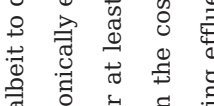

बै

苟

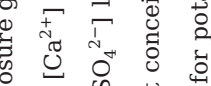

离

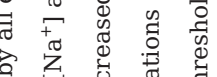

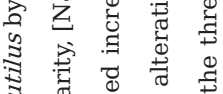

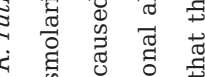

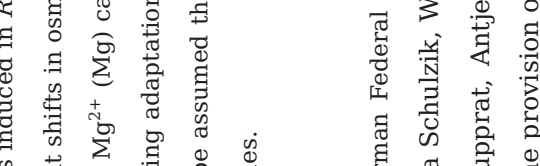

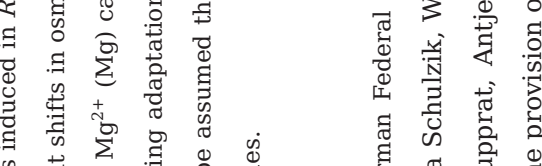

氙

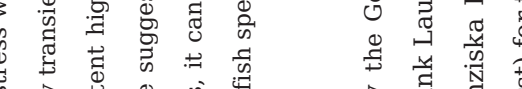

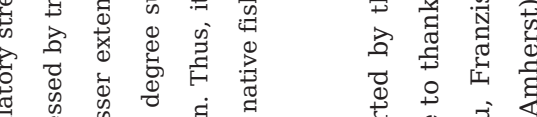

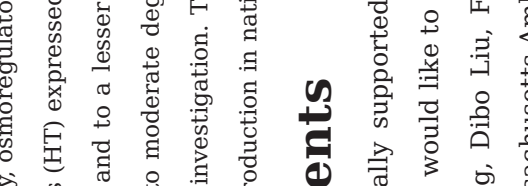

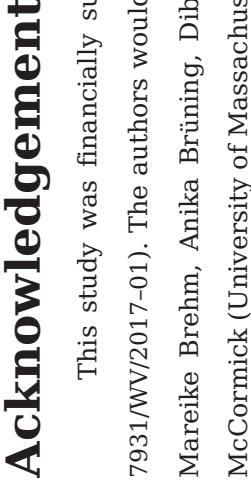

0
0
0
0 


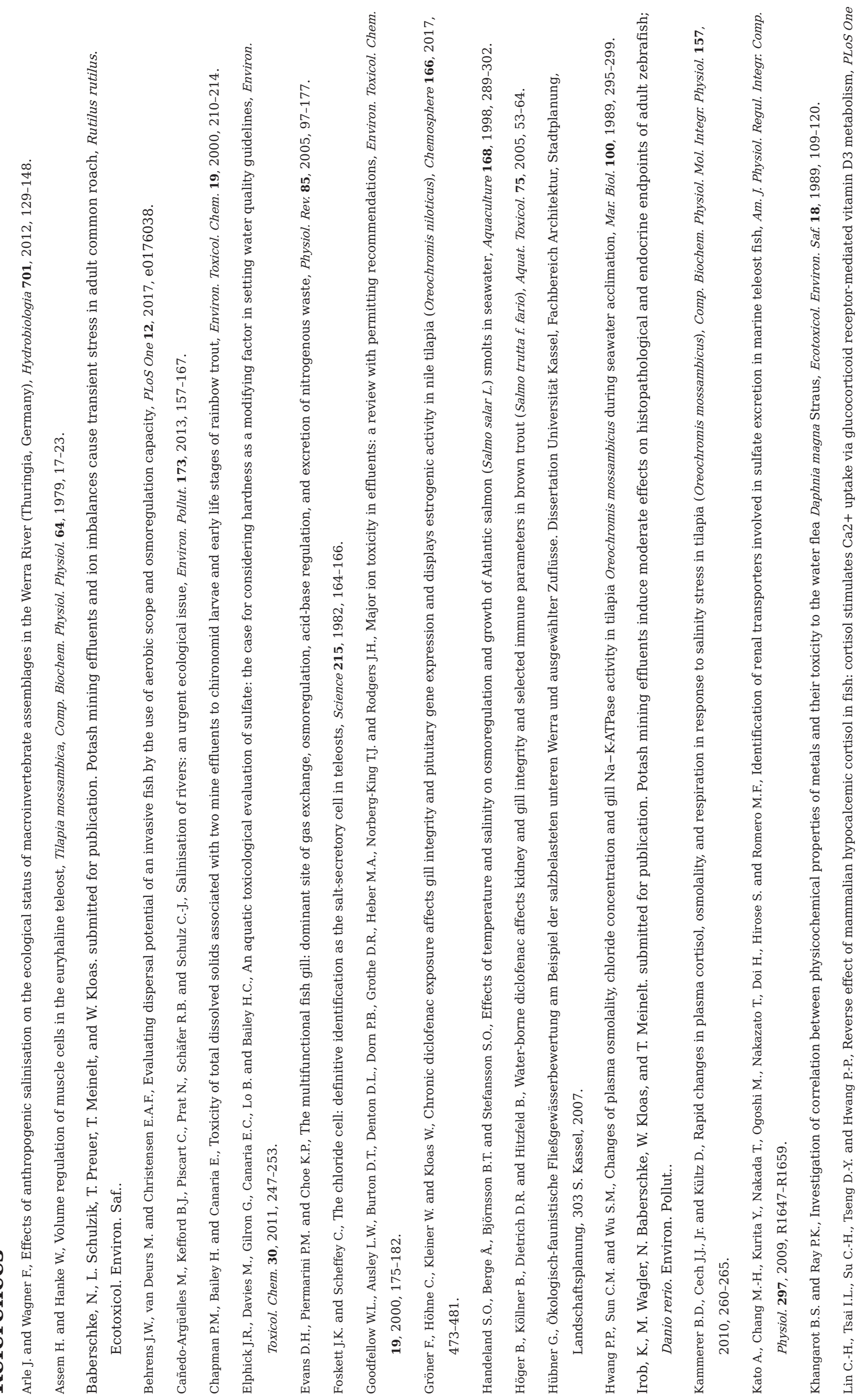




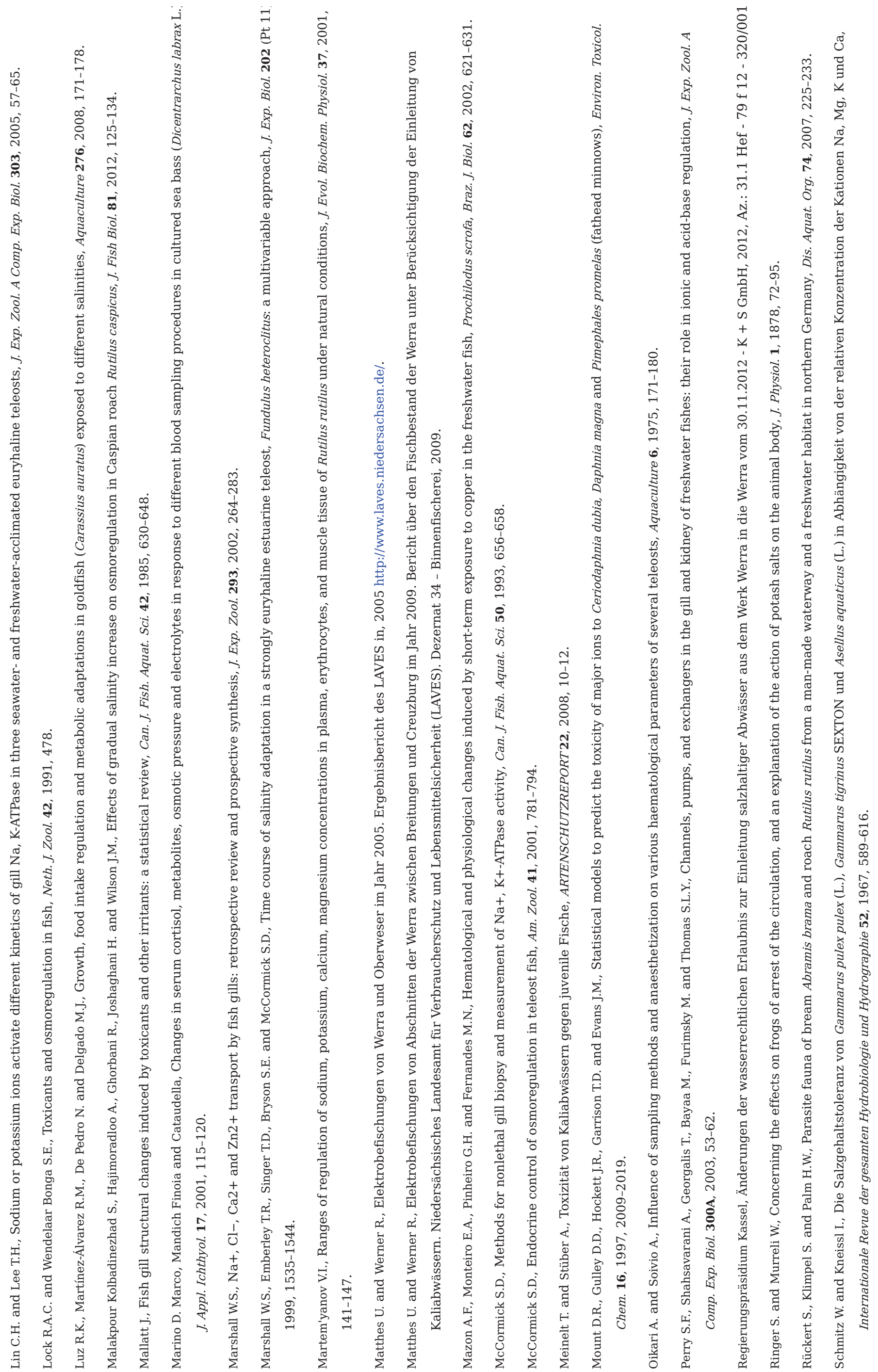



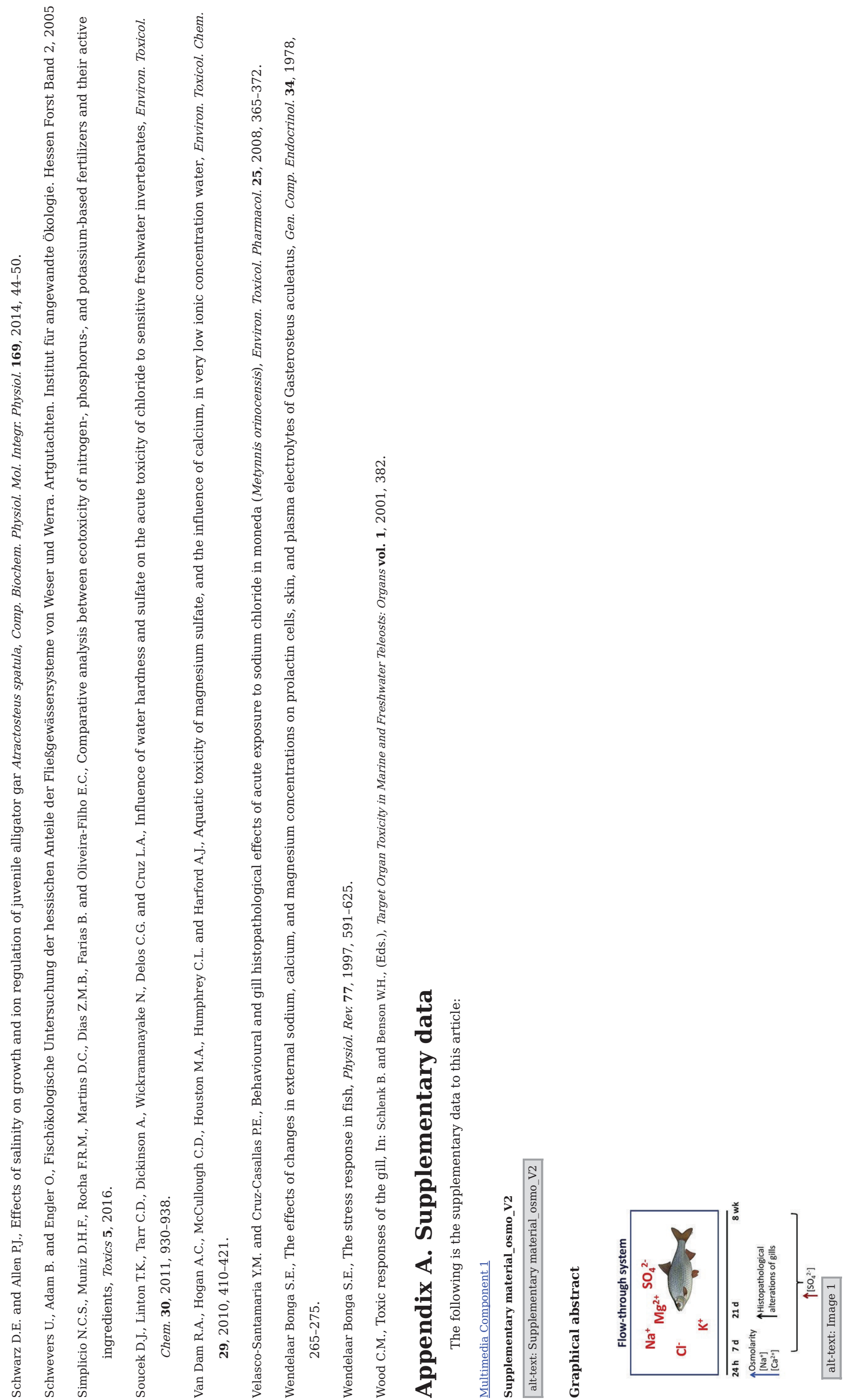